\title{
A Moderating Role of Future Work Self-salience in the Relationship between Proactive Personality and Calling of Student Athletes
}

Wan Chen Lu 1*, Shin-Huei Lin 2, Chiu-Ying Kao 3, Ya-Ling Chen 4

1,4 Department of Athletics, National Taiwan University, Taiwan

2 Department of Leisure Management, National Pingtung University, Taiwan

3 Department of Food and Beverage Management, Shih Chien University, Taiwan

- Background: With the increasing number of sports related college departments and their graduates, the job market of the field of sports has become more competitive than ever. Thus, the key to stand out in such a competitive job market is to foster these college graduates' sense of calling and passion for their careers.

- Method: There were 201 college students from four colleges of sports and physical education department participated in this study. Data were collected through questionnaires.

- Measures: Parker and Sprigg (1999)'s proactive personality scale; Strauss, Griffin \& Parker (2012)'s Future work selves scale; Dik, Eldridge, Steger \& Duffy (2012)'s calling scale.

- Results: Hierarchical regression analysis indicated that future work self-salience could moderate the relationship between proactive personality and calling of student athletes.
- When students with high future work self sailance, the relationship between proactive prsonality and calling became strong. In constract, There is weak relationship between proactive personality and calling when students with low future work self sailance.

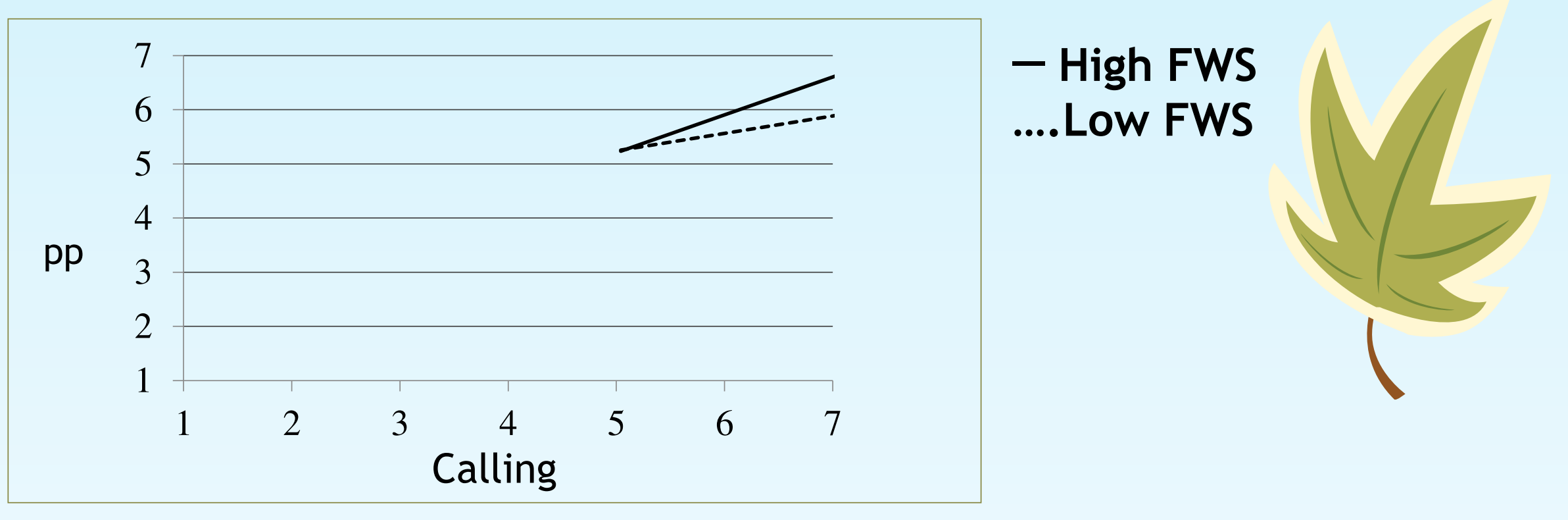

- Conclusions: Future work self-salience could be a key role of calling. By expanding the use of the proactive motivation model, the study could be served as consultation to schools and companies when cultivating student athlete career development.

- E-mail: gracelyu@ntu.edu.tw 